\title{
Determination of lead in plasma and studies on its relationship to lead in erythrocytes
}

\author{
P E DESILVA
}

From the Industrial Hygiene Section, Health Commission of Victoria, Melbourne, Australia

ABSTRACT Plasma lead concentrations were determined in 103 subjects, including lead workers and those not occupationally exposed to lead. The plasma lead concentrations in each blood lead group were about half those previously reported, and this difference was shown to be due to the use of heparin instead of ethylenediaminetetra-acetic acid (EDTA) as the anticoagulant. The method for the determination of lead in plasma is detailed and its accuracy discussed. The plasma lead concentration was found to increase with the erythrocyte lead concentration, the mean equilibrium ratio between the two being about $0.74 \%$. The effect of a sudden disturbance of the equilibrium condition on this ratio was investigated. This work supports the view that whole blood lead concentrations should be corrected for haematocrit.

In 1978 Cavalleri et al ${ }^{1}$ claimed that plasma lead increased progressively and significantly with the increase of whole blood lead, while its relative percentage in the plasma remained practically constant at about $3 \%$ (means ranging from 2.9 to $3.3 \%$ ) for all concentrations in whole blood-that is,

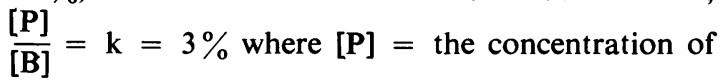
lead in the plasma and $[\mathrm{B}]=$ the concentration of lead in the blood.

This finding is in pronounced contrast to the work of Rosen et al, ${ }^{2}$ who claimed to have shown that plasma concentrations of lead remain constant over a wide range of haematocrit and whole blood lead concentrations-that is, $[\mathrm{P}]=\mathrm{k}=3 \mu \mathrm{g} / 100 \mathrm{ml}$, irrespective of $[\mathrm{B}]$ and haematocrit.

Cavalleri et $a l^{1}$ rightly attribute this difference to the greater sensitivity of their method, and their work certainly shows a degree of accuracy and precision never before achieved in the chemical analysis of lead in plasma. Many other workers ${ }^{3-8}$ have claimed to be able to analyse lead in plasma; but there is no doubt that plasma lead concentrations are below the limits of detection of the methods used and consequently their results must be unequivocally rejected.

Before the work of Cavalleri et al, the only reliable estimates of plasma lead concentrations were arrived at by the radioactive tracer studies of Castellino and Aloj ${ }^{9}$ and Hursh et al. ${ }^{10}$ More recently

Received 14 April 1980

Accepted 13 March 1981
Chamberlain et al ${ }^{11}$ have estimated that less than $0.3 \%$ of ${ }^{203} \mathrm{~Pb}$ present in the blood of three subjects, ten hours after administration, was in the plasma fraction.

The significance of the work of Rosen et $a^{2}$ lies in the fact that it has been widely quoted by many authorities 1213 as having provided evidence to support the view that whole blood lead concentrations should not be corrected for haematocrit. This evidence is based on the claim that plasma lead concentrations are maintained "within narrow limits" and that consequently the erythrocytes have an unlimited capacity for the uptake of lead.

This paper reports a series of plasma lead determinations using an almost identical procedure as did Cavalleri et al, but with the important difference that the blood specimens were collected in heparinised tubes instead of EDTA tubes as used by Cavalleri $e t$ $a l$. This difference has a very significant effect on the accuracy and scatter of the results obtained. Although they state that the plasma was separated from the red cells "immediately" after collection, they do not emphasise this point and are apparently unaware of its importance. In practice it is impossible to collect blood in EDTA tubes and separate the plasma from the red cells without a significant movement of lead from the red cells to the plasma. It will be shown that, even with the centrifuge at the patient's side, the concentration of lead in the plasma when the blood is collected into EDTA tubes is about twice that when collected into heparinised tubes. It follows that the mean ratio of plasma lead concentration to 
whole blood lead concentration was overestimated by Cavalleri et al.

The range and standard deviation of their results in each blood lead group show a larger scatter of results than obtained in this study using heparin tubes. This wider scatter of results is probably also largely due to slight variations in the time taken between the collecting and centrifuging of the blood samples. It is not possible to reduce this time to zero, and there are obvious practical difficulties in making the time uniform, particularly if subjects are being bled in groups.

From a theoretical point of view one would expect that, when a person is in equilibrium, the ratio between the plasma lead concentration $[\mathrm{P}]$ and the erythrocyte lead concentration [E] would be constant-that is, $\frac{[\mathrm{P}]}{[\mathrm{E}]}=\mathrm{k}$.

In this study the plasma lead concentration is compared with the erythrocyte lead concentration. The erythrocyte lead concentration, however, was not measured directly; it was calculated according to the formula

$$
[\mathrm{E}]=\frac{100[\mathrm{~B}]}{\mathrm{Ht}}-\frac{[\mathrm{P}](100-\mathrm{Ht})}{\mathrm{Ht}}
$$

where $[E]=$ erythrocyte lead concentration,

[B] $=$ blood lead concentration,

$[\mathrm{P}]=$ plasma lead concentration, and

$\mathrm{Ht}=$ haematocrit expressed as a percentage.

From a theoretical point of view the objection may be raised that the comparison of [P] with [E] is invalid because [P] was used to calculate [E]. It can be seen, however, that the contribution of $[P]$ to the calculated value of $[E]$ is exceedingly small. Furthermore, the estimation of [E] in this manner offers practical advantages over the direct analysis on packed red cells. The laboratory is experienced in whole blood lead analyses and haematocrit determinations, and the accuracy of both has been carefully established and is under constant review. The laboratory participates in the UK National External Assessment Scheme for Lead in Blood. On the other hand, the analysis of packed red cells is not a routine procedure, and its accuracy has not been thoroughly investigated. There is no external assessment scheme for erythrocyte lead analysis. Consequently, it was decided that the calculation of [E] from [B] and $\mathrm{Ht}$ would be at least as accurate as direct analysis of the packed red cells.

There is no theoretical basis for comparing [P] with [B] as done by Cavalleri. Nevertheless, for the purposes of direct comparison with Cavalleri's work some of the results will be presented in terms of this comparison.
This paper also reports a short series of blood and plasma lead concentrations on a subject who volunteered to ingest a dose of lead on two separate occasions. The subject was a medical practitioner who has had an interest in lead metabolism for many years and participated with full knowledge of the toxicity of lead. The purpose of this investigation was to establish the period required for the equilibrium to be re-established and to investigate the extent of the increase in the ratio $\frac{[P]}{[E]}$ under conditions of rapid absorption.

Part I Determination of lead in plasma in lead workers and "unexposed" subjects

\section{SELECTION OF SUBJECTS}

The aim was to collect about 100 samples distributed as evenly as possible over the available blood lead range with about 20 subjects for each $20 \mu \mathrm{g} / 100 \mathrm{ml}$ $(0.97 \mu \mathrm{mol} / \mathrm{l})$ range of whole blood lead concentrations.

The principle source of the samples was the subjects attending the industrial hygiene section for evaluation of their lead state. These subjects include a high proportion of lead workers (about $60 \%$ ) whose screening coproporphyrin test, normally carried out on the factory premises, had exceeded $1000 \mu \mathrm{g} / 1(1530 \mu \mathrm{mol} / \mathrm{l})$. In addition, there was a miscellaneous group referred by private medical practitioners, whose lead concentrations were mostly in the normal range. There was, therefore, no difficulty in obtaining specimens in the blood lead ranges under $20 \mu \mathrm{g} / 100 \mathrm{ml}(0.97 \mu \mathrm{mol} / \mathrm{l})$ and over 60 $\mu \mathrm{g} / 100 \mathrm{ml}(2.9 \mu \mathrm{mol} / \mathrm{l})$. Between $20 \mu \mathrm{g} / 100 \mathrm{ml}(0.97$ $\mu \mathrm{mol} / \mathrm{l})$ and $60 \mu \mathrm{g} / 100 \mathrm{ml}(2.9 \mu \mathrm{mol} / \mathrm{l})$ some difficulty was experienced in obtaining sufficient samples. For this reason, 23 of the 105 samples were obtained by visiting two factories and collecting blood from volunteers whose exposure to lead was moderate.

Thus lead concentrations in plasma were determined in 103 individuals (two results were excluded - see later) with blood lead concentrations ranging from $5 \mu \mathrm{g} / 100 \mathrm{ml}(0 \cdot 24 \mu \mathrm{mol} / \mathrm{l})$ to $109 \mu \mathrm{g} / 100 \mathrm{ml}$ $(5.26 \mu \mathrm{mol} / 1)$. The numbers in each group are shown in table 1.

\section{SAMPLE COLLECTION}

About $12 \mathrm{ml}$ of blood was withdrawn by venepuncture and placed in a heparinised blood collecting tube (see method). About $2 \mathrm{ml}$ of this blood was used for routine blood lead analysis carried out by another analyst, using a carbon rod atomic absorption method with direct application of haemolysed blood to the rod. ${ }^{14}$ The remaining $10 \mathrm{ml}$ was centrifuged for $20 \mathrm{~min}$ at $3500 \mathrm{rpm}$. 
Table 1 Plasma lead concentrations in 103 subjects compared with erythrocyte lead concentrations

\begin{tabular}{|c|c|c|c|c|c|c|c|}
\hline \multicolumn{2}{|c|}{$\begin{array}{l}\text { Range of erythrocyte lead } \\
\text { concentrations }\end{array}$} & \multirow{2}{*}{$\begin{array}{l}\text { No of } \\
\text { subjects }\end{array}$} & \multicolumn{2}{|c|}{ Mean plasma lead concentrations } & \multicolumn{2}{|c|}{ Range of plasma lead concentrations } & \multirow{2}{*}{$\frac{[P]}{[E]} \pm S D$} \\
\hline$(\mu \mathrm{g} / 100 \mathrm{ml})$ & $(\mu \mathrm{mol} / \mathrm{l})$ & & $\begin{array}{l}(\mu g / 100 \\
m l \pm S D)\end{array}$ & $(\mu m o l / l \pm S D)$ & $(\mu \mathrm{g} / 100 \mathrm{ml})$ & $(\mu \mathrm{mol} / \mathrm{l})$ & \\
\hline $\begin{array}{r}\leqslant 39 \\
40-79 \\
80-119 \\
120-159 \\
160-199 \\
\geqslant 200\end{array}$ & $\begin{array}{r}\leqslant 1 \cdot 9 \\
1 \cdot 9-3 \cdot 8 \\
3 \cdot 9-5 \cdot 8 \\
5 \cdot 8-7 \cdot 7 \\
7 \cdot 7-9 \cdot 6 \\
\geqslant 9 \cdot 6\end{array}$ & $\begin{array}{r}18 \\
12 \\
20 \\
27 \\
22 \\
4\end{array}$ & $\begin{array}{l}0.27 \pm 0.11 \\
0.48 \pm 0.22 \\
0.69 \pm 0.25 \\
0.99 \pm 0.40 \\
1.43 \pm 0.77 \\
2.64 \pm 0.78\end{array}$ & $\begin{array}{l}0.013 \pm 0.005 \\
0.023 \pm 0.011 \\
0.033 \pm 0.012 \\
0.048 \pm 0.019 \\
0.069 \pm 0.037 \\
0.128 \pm 0.038\end{array}$ & $\begin{array}{l}0.14 \rightarrow 0.57 \\
0.17 \rightarrow 0.84 \\
0.26 \rightarrow 1.16 \\
0.38 \rightarrow 1.48 \\
0.48 \rightarrow 3.96 \\
1.64 \rightarrow 3.42\end{array}$ & $\begin{array}{l}0.007 \rightarrow 0.028 \\
0.008 \rightarrow 0.041 \\
0.013 \rightarrow 0.056 \\
0.018 \rightarrow 0.072 \\
0.023 \rightarrow 0.191 \\
0.078 \rightarrow 0.165\end{array}$ & $\begin{array}{l}1.0 \pm 0.4 \\
0.8 \pm 0.3 \\
0.7 \pm 0.2 \\
0.7 \pm 0.3 \\
0.8 \pm 0.4 \\
1.2 \pm 0.3\end{array}$ \\
\hline
\end{tabular}

As the number of subjects attending the section in any one day was usually under six, the specimens were collected serially and then centrifuged together, resulting in a delay of about $30 \mathrm{~min}$ for the first specimen collected. It was shown, however, that no change in plasma lead occurred if the specimens were left in heparinised tubes for up to two hours before separation, and therefore this time was not critical. The 23 specimens collected in two factories could not be centrifuged within $30 \mathrm{~min}$, the first ones collected being subject to a delay of up to two hours before separation.

The plasma was removed and placed in a second tube and centrifuged again. The second centrifuging was considered necessary to ensure that no red cells were left in the plasma fraction. This second tube usually showed a few red cells at the bottom; but the plasma for analysis could be pipetted off the top without disturbing the cells. Duplicate $2 \mathrm{ml}$ aliquots of plasma were pipetted and analysed within 24 hours if possible, but otherwise frozen for later analysis. The whole blood lead determinations were performed routinely on the day of collection.

\section{DESIGN OF THE STUDY}

All analyses of plasma lead were carried out blind with respect to the whole blood lead concentration.

Of the 105 samples, 84 were analysed in duplicate, blind with respect to which were the duplicates in each batch. It was considered unreasonable to take duplicate venepuncture samples from each subject, and the duplication therefore starts after the separation of the plasma, and is thus a measure of the reproducibility of the analysis within one batch.

The analyses were performed in batches of 14 , consisting of ten tests (usually five subjects in duplicate), three standards, and one blank. This was the maximum number that could be done in half a day, including preparation and atomic absorption work. Each solvent layer was injected a minimum of three times, the exact number of injections depending on their reproducibility.

\section{METHOD}

The method employed for the plasma lead deter- mination is based on the chelation solvent-extraction procedure of Hessel ${ }^{15}$ and is similar to that used by Cavalleri et al. ${ }^{1}$ It will be presented here in some detail because of the great importance of such factors as accuracy and precision and the prevention of contamination.

\section{Apparatus}

All determinations were performed using a varian atomic absorption spectrophotometer (AA-175B) with a varian carbon rod atomiser (CRA-90).

Extreme care was taken to avoid contamination of any of the glassware, centrifuge tubes, or bloodcollecting tubes. Blood-collecting tubes were prepared using polypropylene centrifuge tubes of about $15 \mathrm{ml}$ capacity. Only new tubes were used, and these were washed by soaking overnight, first in detergent and then in $10 \%$ nitric acid. They were heparinised by adding $0.1 \mathrm{ml}$ of $1 \%$ aqueous sodium heparin per tube and drying the tubes in the oven. Commercially available heparinised blood-collecting tubes, while quite satisfactory for whole blood lead determination, were found to release about $10 \mathrm{ng}$ of lead to $5 \mathrm{ml}$ of plasma added to the tubes and rotated for 15 minutes, which is equivalent to a plasma lead concentration of $0.20 \mu \mathrm{g} / 100 \mathrm{ml}(0.010 \mu \mathrm{mol} / \mathrm{l})$. Whereas this amount of lead is insignificant in relation to a whole blood lead level, it is about equal to the concentration of lead in the plasma of "normal" individuals. The same polypropylene tubes were used for the second centrifugation and also for the reaction vessels.

\section{Blank value}

A blank determination was performed in every batch as a continuing check on the cleanliness of the apparatus and the purity of the reagents.

All reagents were tested for lead content, the only one with a significant amount being the methyl isobutyl ketone. This could not be removed by distillation and collection of the centre fraction only. Several batches of methyl isobutyl ketone were tested, and the best was selected. The mean value of the reagent blank (due almost entirely to methyl isobutyl ketone) was equivalent to a plasma lead 


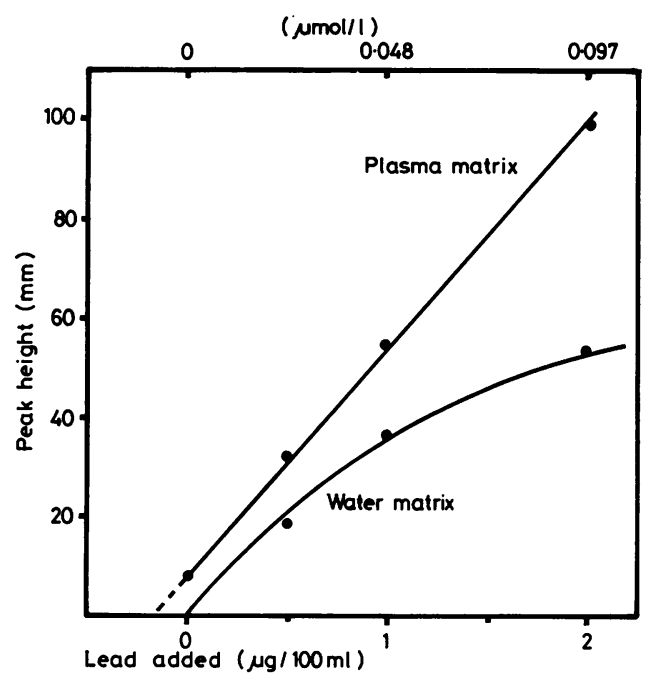

Fig 1 Calibration graphs with plasma and with water matrix.

value of $0.06 \mu \mathrm{g} / 100 \mathrm{ml}(0.003 \mu \mathrm{mol} / \mathrm{l})$, and its standard deviation was $0.03 \mu \mathrm{g} / 100 \mathrm{ml}(0.001 \mu \mathrm{mol} / \mathrm{l})$. Using the definitions of detection limit and determination limit proposed by Currie, ${ }^{16}$ the detection limit of the method is $0.10 \mu \mathrm{g} / 100 \mathrm{ml}(0.005 \mu \mathrm{mol} / \mathrm{l})$ and the determination limit is $0.30 \mu \mathrm{g} / 100 \mathrm{ml}(0.015$ $\mu \mathrm{mol} / \mathrm{l})$, assuming that the maximum acceptable relative standard deviation for quantitative analysis is $10 \%$; if one is prepared, of necessity, to accept a relative standard deviation of $20 \%$ the determination limit is $0.15 \mu \mathrm{g} / 100 \mathrm{ml}(0.007 \mu \mathrm{mol} / \mathrm{l})$.

\section{Calibration}

In the standard chelation solvent-extraction whole blood lead method (flame atomic absorption) it is possible to use aqueous lead solutions to prepare a calibration graph. An attempt was made to use similar standards for the carbon rod method; but a matrix effect was evident, which is apparently not a problem with the flame method. The extent of this matrix effect is shown in fig 1 .

It was therefore necessary to use the "standard additions" technique-that is, to prepare calibration graphs by the addition of known amounts of lead to plasma and to determine the amount of lead originally present in the plasma (the "endogenous" lead) by extrapolation.

Two hundred millilitres of plasma was obtained on three occasions from volunteers with no special exposure to lead, pipetted into $2 \mathrm{ml}$ aliquots and frozen. Freezing of the plasma after aliquoting was unavoidable, although it resulted in the separation of the fibrin in each aliquot.
On the day of analysis at least three of these tubes were thawed, and known amounts of lead were added. The standard lead solution contained $0.1 \mathrm{mg}$ $\mathrm{Pb} / \mathrm{l}(0.48 \mu \mathrm{mol} / \mathrm{l})$ and was prepared fresh daily from a stock solution containing $10 \mathrm{mg} \mathrm{Pb} / 1(48 \mu \mathrm{mol} / \mathrm{l})$.

Calibration graphs were prepared on each day for each batch of ten analyses. The slope of the calibration graph varied from day to day apparently depending on the instrument conditions; but the sensitivity (that concentration of lead in plasma at which the absorbance equals 0.0044 ) was never less than $0.06 \mu \mathrm{g} / 100 \mathrm{ml}(0.0029 \mu \mathrm{mol} / \mathrm{l})$ and was usually about $0.03 \mu \mathrm{g} / 100 \mathrm{ml}(0.0014 \mu \mathrm{mol} / \mathrm{l})$.

A typical calibration graph is shown in fig 1 (plasma matrix).

\section{Procedure}

A $2 \mathrm{ml}$ aliquot of plasma is pipetted into a polypropylene tube. To this is added $0.5 \mathrm{ml}$ of a $2 \%$ aqueous ammonium pyrrolidine dithiocarbamate (APDC) solution and the tube capped, inverted 20 times, and allowed to stand for $5 \mathrm{~min}$. One millilitre of methyl isobutyl ketone is added and the tube mixed on a rotating mixer $(30 \mathrm{rpm})$ for $3 \mathrm{~min}$, after which the tube is centrifuged immediately for $20 \mathrm{~min}$ at $3500 \mathrm{rpm}$.

Ten microlitre aliquots (two injections, each of 5 $\mu l)$ of the solvent layer are then injected into the graphite furnace using an SGE $5 \mu \mathrm{l}$ syringe with disposable plastic tips. When the peak height is greater than about $80 \mathrm{~mm}$ the calibration may not be linear. In these cases $5 \mu \mathrm{l}$ injections are used. Injections are carried out during the drying cycle to ensure rapid evaporation of solvent and prevent it spreading over the rod.

The instrument conditions used are: wavelength $217 \mathrm{~nm}$, slit width $0.5 \mathrm{~nm}$, lamp current $8 \mathrm{~mA}$, recorder $50 \mathrm{mV}$. The heating programme on the CRA-90 is: dry at $100^{\circ} \mathrm{C}$ for $70 \mathrm{~s}$, ash at $450^{\circ} \mathrm{C}$ for $20 \mathrm{~s}$, atomise at $2000^{\circ} \mathrm{C}$ with a ramp rate of $800^{\circ} \mathrm{C} / \mathrm{s}$ and a hold time of $2 \mathrm{~s}$. Simultaneous background correction is used.

The height of the atomise peak is measured and the concentration of lead in the plasma read directly off the calibration graph, having adjusted the scale on the horizontal axis to allow for the endogenous lead in the standard plasma.

\section{Accuracy and precision}

Assessment of the accuracy of the method presents some difficulty. No other independent methods are in common use, and it is not possible to compare the results obtained with those obtained by another experienced laboratory using a different method.

With regard to recovery studies, the method of standard additions is somewhat different from many 
other methods in that there is no difference between a "recovery" and a "standard," except that the recovery is done "blind." There is little opportunity for serious and varied losses of lead such as can occur with procedures entailing the destruction of organic matter by heating and for which recoveries are a valuable means of assessing losses of lead.

The many calibration graphs prepared during preliminary work on the method gave a good indication that the method was accurate provided that "endogenous" lead behaved in the same way as "added" lead. All the points on these graphs fell very closely either on to a straight line or on to a line with a very slight degree of curvature.

It was decided to collect further data on accuracy and precision throughout the conduct of the study rather than as a separate preliminary exercise, as carried out by Cavalleri et al. ${ }^{1}$ Preliminary estimations of a method's accuracy and precision do not guarantee that the same standards will be maintained throughout the investigation. It should always be regarded as essential to demonstrate the accuracy and precision achieved during the course of any study.

Thus 88 of the 105 analyses were done in blind duplicate. Two of the pairs of duplicates have been excluded because the large differences between them of $0.60 \mu \mathrm{g} / 100 \mathrm{ml}(0.029 \mu \mathrm{mol} / \mathrm{l})$ and $0.66 \mu \mathrm{g} / 100 \mathrm{ml}$ $(0.032 \mu \mathrm{mol} / \mathrm{l})$ indicate that relatively serious contamination must have occurred. The mean difference between the remaining 86 duplicates was $0.092 \mu \mathrm{g} / 100 \mathrm{ml}(0.0044 \mu \mathrm{mol} / \mathrm{l})$. The distribution of the difference showed that 65 of the 86 duplicates $(76 \%)$ were $<0.14 \mu \mathrm{g} / 100 \mathrm{ml}(0.0068 \mu \mathrm{mol} / \mathrm{l})$ apart. The distribution of the percentage difference showed that 68 of the 86 duplicates $(79 \%)$ were $<20 \%$ apart.

For the reasons indicated above, only nine blind recoveries were carried out. For seven of these, the added lead ranged from $0.56 \mu \mathrm{g} / 100 \mathrm{ml}(0.027$ $\mu \mathrm{mol} / \mathrm{l})$ to $1.72 \mu \mathrm{g} / 100 \mathrm{ml}(0.083 \mu \mathrm{mol} / \mathrm{l})$, and a mean recovery of $99 \%$ was obtained. For two, the added lead was only $0.06 \mu \mathrm{g} / 100 \mathrm{ml}(0.0029 \mu \mathrm{mol} / \mathrm{l})$ and $0.12 \mu \mathrm{g} / 100 \mathrm{ml}(0.0058 \mu \mathrm{mol} / \mathrm{l})$, and recoveries of $50 \%$ and $67 \%$ respectively were obtained. These results confirm that the limit of detection is about $0 \cdot 1 \mu \mathrm{g} / 100 \mathrm{ml}(0.0048 \mu \mathrm{mol} / \mathrm{l})$ and that accurate results will not be obtained below about $0 \cdot 3 \mu \mathrm{g} / 100$ $\mathrm{ml}(0.015 \mu \mathrm{mol} / \mathrm{l})$.

Two other factors, although not quantifiable, contribute to one's confidence that the method has reliably measured the lead level in plasma. These are:

(a) the demonstration of a highly significant regression coefficient in the regression equation showing the relationship between plasma lead concentration and erythrocyte lead concentration (see "results"), and

(b) the results of the in-vivo studies after the ingestion of lead (see part II), which were consistent with theoretical expectations.

While none of the procedures detailed above regarded separately is proof that the method is accurate, together they provide considerable evidence to that effect.

\section{RESULTS}

Figure 2 is a scattergram of the results of the plasma lead concentration against the erythrocyte lead concentration and illustrates the interdependence of $[P]$ and [E].* This interdependence cannot be explained by the fact that the value of $[P]$ is used in the calculation of $[E]$ because its contribution to the value of $[E]$ is insignificant.

Because the study sample was contrived and therefore not normally distributed, the correlation coefficient cannot be used to demonstrate the relationship between the two variables. The relationship, however, can be represented by the regression equation $y=0.009 x-0.13$ where $y=$ the predicted plasma lead concentration in $\mu \mathrm{g} / 100 \mathrm{ml}$, and $x=$ the erythrocyte lead concentration in $\mu \mathrm{g} / 100 \mathrm{ml}$. The regression coefficient 0.009 is highly significant, its standard error being \pm 0.0008 ( $p<0.001)$; but the constant is not significantly different from zero $(t$ test). The $95 \%$ confidence limits of $y$ about the regression line are $\pm 0.9 \mu \mathrm{g} / 100 \mathrm{ml}(0.044 \mu \mathrm{mol} / \mathrm{l})$.

Examination of the scattergram shows four points

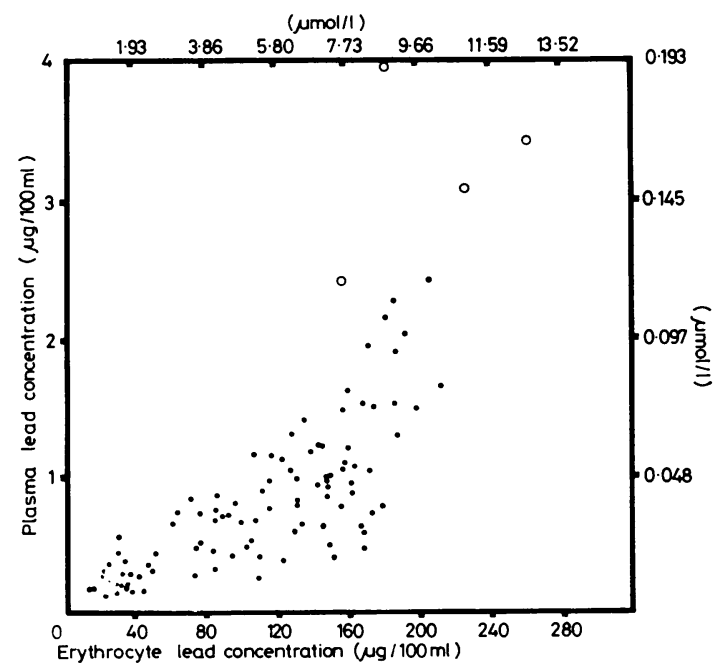

Fig 2 Relation between plasma lead concentration and erythrocyte lead concentration.

*Detailed results are available from the author. 
(circled) which have a disproportionate effect on the slope of the regression line, and these points will be considered in the discussion section.

Table 1 shows the means, standard deviations, and ranges of the plasma lead concentrations taken in groups according to the erythrocyte concentrations and the $\frac{[P]}{[E]}$ ratio for each group.

The plasma lead concentrations increase progressively with the erythrocyte lead concentrations and the mean $\frac{[\mathrm{P}]}{[\mathrm{E}]}$ ratio for each group is almost constant, at least up to an erythrocyte lead concentration of $199 \mu \mathrm{g} / 100 \mathrm{ml}(9 \cdot 61 \mu \mathrm{mol} / \mathrm{l})$. The results in the first group are subject to greater inaccuracy than the other groups, in the determination of both the plasma lead concentration and the erythrocyte lead concentration, and the slightly higher ratio in this group is most likely due to these inaccuracies. For the last group of four subjects with erythrocyte lead concentration greater than $199 \mu \mathrm{g} / 100 \mathrm{ml}(9.61$ $\mu \mathrm{mol} / \mathrm{l})$, the ratio is $1.2 \%$, which is significantly different at the $2 \%$ level (Wilcoxon two sample rank sum test) from the ratio of $0.74 \%$ (standard deviation $0.31 \%$ ) calculated using the results from the 81 subjects in the four intermediate groups with erythrocyte lead concentrations between $40 \mu \mathrm{g} / 100$ $\mathrm{ml}(1.9 \mu \mathrm{mol} / \mathrm{l})$ and $199 \mu \mathrm{g} / 100 \mathrm{ml}(9.6 \mu \mathrm{mol} / \mathrm{l})$. The possible reasons for this will be considered in the discussion section. The regression equation using the most accurate results from these 81 subjects (56 duplicate results under $20 \%$ apart) is $y=0.0075$ $x-0.01$, and this would be the most accurate prediction equation, provided the subject had not experienced an unusually high lead intake within the previous 24 hours.

The relationship $\frac{[\mathrm{P}]}{[\mathrm{E}]}=k$ can also be expressed as $[\mathrm{P}] \simeq k \frac{[\mathrm{B}]}{\mathrm{Ht}}$. Over the small range encompassed in the normal variations of $\mathrm{Ht}$ this relationship is approximate to $[\mathrm{P}]=a+b[\mathrm{~B}]-c \mathrm{Ht}$.

This makes legitimate the application of multiple regression analysis to the results and this analysis yields the following multiple regression equation $y=1.09+0.020 x_{1}-0.028 x_{2}$ where $y=$ the predicted plasma lead concentration in $\mu \mathrm{g} / 100 \mathrm{ml}$, $x_{1}=$ the whole blood lead concentration in $\mu \mathrm{g} / 100$ $\mathrm{ml}$, and $x_{2}=$ the haematocrit as a percentage. The partial regression coefficient for the blood lead concentration $(0.020)$ is significant at the $1 \%$ level and for the haematocrit value $(-0.028)$ at the $2 \%$ level ( $t$ test). If the equation is derived using only those duplicate results under $20 \%$ apart, however, the regression coefficient for the haematocrit value is also significant at the $1 \%$ level. The equation using these results is $y=2 \cdot 11+0.020 x_{1}-0.049 x_{2}$.

It follows from the form of the multiple regression equation (a positive coefficient of $x_{1}$ and a negative coefficient of $x_{2}$ ) that

(1) with a constant value of the haematocrit $\left(x_{2}\right)$ the plasma lead concentration increases with increase in blood lead concentration and

(2) with a constant value of the blood lead concentration $\left(x_{1}\right)$ the plasma lead concentration decreases with increase in the haematocrit value.

Table 2 Plasma lead concentration, blood lead concentration, and $\frac{[P]}{[E]}$ after a high intake of lead

\begin{tabular}{|c|c|c|c|c|c|c|c|c|c|}
\hline \multirow[t]{2}{*}{ Date } & \multirow{2}{*}{$\begin{array}{l}\text { Time of } \\
\text { specimen }\end{array}$} & \multirow{2}{*}{$\begin{array}{l}\text { Time after } \\
\text { dose }(h)\end{array}$} & \multicolumn{2}{|l|}{$[P]$} & \multicolumn{2}{|l|}{$[B]$} & \multicolumn{2}{|l|}{$[E]$} & \multirow{2}{*}{$\begin{array}{l}\frac{[P]}{[E]} \\
(\%)\end{array}$} \\
\hline & & & $\mu \mathrm{g} / 100 \mathrm{ml}$ & $\mu \mathrm{mol} / \mathrm{l}$ & $\mu \mathrm{g} / 100 \mathrm{ml}$ & $\mu \mathrm{mol} / \mathrm{l}$ & $\mu \mathrm{g} / 100 \mathrm{ml}$ & $\mu \mathrm{mol} / \mathrm{l}$ & \\
\hline \multicolumn{10}{|c|}{ First study (7.8.79) } \\
\hline 7. 8.79 & $630 \mathrm{am}$ & $\mathbf{0}$ & 0.57 & 0.028 & 16 & $0 \cdot 77$ & 33 & $1 \cdot 59$ & $1 \cdot 7$ \\
\hline \multicolumn{10}{|c|}{$100 \mathrm{mg}$ of lead ingested at $635 \mathrm{am}$} \\
\hline 7. 8.79 & 830 am & 2 & $4 \cdot 90$ & 0.237 & 78 & $3 \cdot 77$ & 176 & $8 \cdot 50$ & $3 \cdot 2$ \\
\hline & $1030 \mathrm{am}$ & 4 & $2 \cdot 58$ & $0 \cdot 125$ & 70 & $3 \cdot 38$ & 146 & $7 \cdot 05$ & $1 \cdot 8$ \\
\hline & $1230 \mathrm{pm}$ & 6 & 3.06 & $0 \cdot 148$ & 68 & $3 \cdot 28$ & 138 & 6.67 & $2 \cdot 2$ \\
\hline & $430 \mathrm{pm}$ & 10 & $2 \cdot 36$ & $0 \cdot 114$ & 63 & 3.04 & 133 & $6 \cdot 42$ & $1 \cdot 7$ \\
\hline 8. 8.79 & $830 \mathrm{am}$ & 26 & $1 \cdot 22$ & 0.059 & 54 & $2 \cdot 61$ & 116 & $5 \cdot 60$ & $1 \cdot 1$ \\
\hline 10. 8.79 & $830 \mathrm{am}$ & 74 & 1.03 & 0.050 & 49 & $\mathbf{2 \cdot 3 7}$ & 99 & $4 \cdot 78$ & $1 \cdot 0$ \\
\hline 13. 8.79 & $1130 \mathrm{am}$ & 149 & 0.69 & 0.033 & 42 & $2 \cdot 03$ & 91 & $4 \cdot 40$ & 0.7 \\
\hline 16. 8.79 & $1130 \mathrm{am}$ & 221 & 0.69 & 0.033 & 37 & $1 \cdot 79$ & 76 & 3.67 & 0.9 \\
\hline \multicolumn{10}{|c|}{ Second study (10.12.79) } \\
\hline 10.12.79 & $800 \mathrm{am}$ & 0.0 & 0.39 & 0.019 & 18 & 0.87 & 37 & 0.77 & $1 \cdot 0$ \\
\hline \multicolumn{10}{|c|}{$100 \mathrm{mg}$ of lead ingested at $805 \mathrm{am}$} \\
\hline 10.12.79 & $900 \mathrm{am}$ & $1 \cdot 0$ & 1.59 & 0.077 & 36 & $1 \cdot 74$ & 73 & 3.53 & $2 \cdot 2$ \\
\hline & $930 \mathrm{am}$ & $1 \cdot 5$ & $1 \cdot 53$ & 0.074 & 42 & $2 \cdot 03$ & 88 & $4 \cdot 25$ & $\overline{1} \cdot \overline{7}$ \\
\hline & $1000 \mathrm{am}$ & $2 \cdot 0$ & 1.69 & 0.082 & 46 & $2 \cdot 22$ & 96 & $4 \cdot 64$ & $1 \cdot 8$ \\
\hline & $1030 \mathrm{am}$ & $2 \cdot 5$ & 1.45 & 0.070 & 46 & $2 \cdot 22$ & 96 & $4 \cdot 64$ & $1 \cdot 5$ \\
\hline & $1100 \mathrm{am}$ & $3 \cdot 0$ & $1 \cdot 26$ & 0.061 & 43 & $2 \cdot 08$ & 88 & $4 \cdot 25$ & 1.4 \\
\hline & $415 \mathrm{pm}$ & $8 \cdot 3$ & $1 \cdot 16$ & 0.056 & 43 & 2.08 & 88 & $4 \cdot 25$ & $1 \cdot 3$ \\
\hline 11.12 .79 & $800 \mathrm{am}$ & $24 \cdot 0$ & 0.84 & 0.041 & 42 & $2 \cdot 03$ & 88 & $4 \cdot 25$ & $1 \cdot 0$ \\
\hline 12.12 .79 & $800 \mathrm{am}$ & $48 \cdot 0$ & 0.66 & 0.032 & 38 & $1 \cdot 84$ & 82 & 3.96 & 0.8 \\
\hline
\end{tabular}




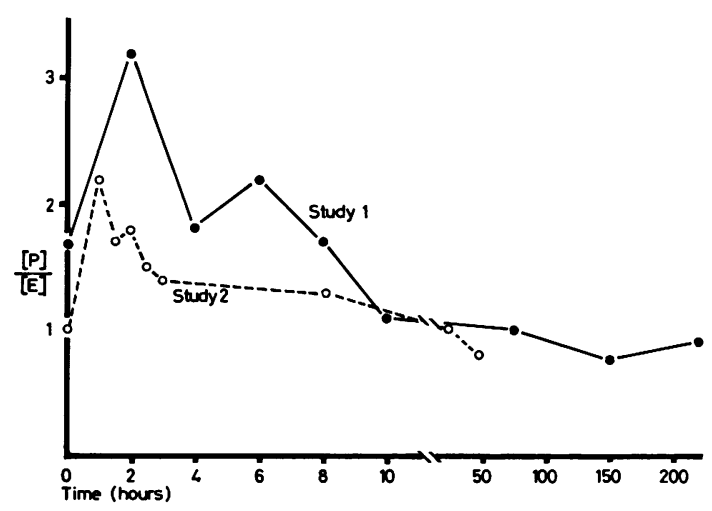

Fig 3 Ratio $\frac{[P]}{[E]}$ after a sudden intake of lead.

Thus the relation $[\mathrm{P}] \simeq k \frac{[\mathrm{B}]}{\mathrm{Ht}}$ is clearly demonstrated.

Part II Effect of a sudden intake of lead on the ratio $\frac{[P]}{[E]}$

The ratio of plasma lead concentration to erythrocyte lead concentration in any individual may well be constant when the subject is in equilibrium. Significant increases in the ratio, however, may be expected to result from sudden departures from equilibrium which are likely to occur when there is a sudden increase in the subject's exposure to lead. It was therefore decided to investigate a situation where an equilibrium condition was suddenly disturbed.

On two separate occasions, four months apart, a volunteer without any special exposure to lead, ingested $100 \mathrm{mg}$ of lead as lead acetate.

FIRST STUDY (7 August 79)

A sample of blood was taken at $600 \mathrm{am}$ after which the lead was ingested, the subject having fasted since the previous evening. Blood samples were then taken at two-hourly intervals for the remainder of the day, once on the next day, and occasionally over the next few days.
The volume of blood collected was half that usually used because so many samples had to be taken in the one day. The tests could not therefore be carried out in duplicate. The results are shown in table 2 and fig 3.

They show that the ratio was $3.2 \%$ two hours after ingestion of lead, about four times the mean ratio expected from the part I study. The higher than average predose ratio of 1.7 is probably due to the greater inaccuracy of both the plasma lead analysis and the whole blood lead analysis at this low level. The ratio fell from $3 \cdot 2$ to $1 \cdot 1$ in 26 hours.

SECOND STUDY (10 December 79)

The study was repeated after the blood lead value had returned to normal. The main reason for the repeat study was to reduce the time interval between the first few samples in case the peak concentration had been achieved within the first two hours. The blood lead concentration rose more slowly than in the first study, reaching a peak of only $46 \mu \mathrm{g} / 100 \mathrm{ml}(2 \cdot 22$ $\mu \mathrm{mol} / \mathrm{l})$ compared with $78 \mu \mathrm{g} / 100 \mathrm{ml}(3.77 \mu \mathrm{mol} / \mathrm{l})$, despite the fact that the same dose of lead was given. This may have been due to the fact that the subject's fluid intake was much higher in the second study and slowed down the absorption of lead from the gut. Nevertheless, the ratio rose from $1.0 \%$ to $2 \cdot 2 \%$, one hour after ingestion and fell to the predose level of $1.0 \%$ after 24 hours. The results are shown in table 2 and fig 3 .

\section{Discussion}

The plasma lead concentrations in this study are significantly lower than those obtained by Cavalleri et al..$^{1}$ Table 3 compares the results of this study with theirs. The lower concentrations and somewhat smaller ranges are attributed to the use of heparinised tubes instead of EDTA tubes.

The effect of EDTA on the plasma lead concentration is significant, even when the blood is centrifuged with as little delay as possible. Samples of blood from six subjects were divided into two parts, one

Table 3 Comparison of results with those of Cavalleri et al ${ }^{1}$

\begin{tabular}{|c|c|c|c|c|c|c|c|c|}
\hline \multicolumn{5}{|l|}{ This study } & \multicolumn{4}{|c|}{ Cavalleri et al } \\
\hline $\begin{array}{l}\text { Range of } \\
\text { whole blood } \\
\text { lead } \\
\text { concentrations } \\
(\mu \mathrm{g} / 100 \mathrm{ml})\end{array}$ & $\begin{array}{l}\text { No of } \\
\text { subjects }\end{array}$ & $\begin{array}{l}\text { Plasma lead } \\
(\mu g / 100 \\
m l \pm S D)\end{array}$ & $\begin{array}{l}\text { Range of } \\
\text { plasma lead } \\
\text { concentrations } \\
(\mu \mathrm{g} / 100 \mathrm{ml})\end{array}$ & $\frac{[P]}{[B]} \pm S D$ & $\begin{array}{l}\text { No of } \\
\text { subjects }\end{array}$ & $\begin{array}{l}\text { Plasma lead } \\
(\mu g / 100 \\
m l \pm S D)\end{array}$ & $\begin{array}{l}\text { Range of } \\
\text { plasma lead } \\
\text { concentrations } \\
(\mu \mathrm{g} / 100 \mathrm{ml})\end{array}$ & $\frac{[P]}{[B]} \pm S D$ \\
\hline $\begin{array}{r}\leqslant 20 \\
21-40 \\
41-80 \\
>80\end{array}$ & $\begin{array}{l}20 \\
13 \\
54 \\
16\end{array}$ & $\begin{array}{l}0.28 \pm 0.11 \\
0.51 \pm 0.22 \\
0.92 \pm 0.40 \\
1.96 \pm 0.90\end{array}$ & $\begin{array}{l}0.14 \rightarrow 0.57 \\
0.17 \rightarrow 0.84 \\
0.26 \rightarrow 2.02 \\
0.77 \rightarrow 3.96\end{array}$ & $\begin{array}{l}2.4 \pm 1.2 * \\
1.6 \pm 0.6 \\
1.5 \pm 0.6 \\
2.2 \pm 0.9\end{array}$ & $\begin{array}{c}30 \\
34 \\
17 \\
12\end{array}$ & $\begin{array}{l}0.54 \pm 0.16 \\
0.61 \pm 0.24 \\
1.69 \pm 0.96 \\
4.42 \pm 3.75\end{array}$ & $\begin{array}{l}0.3 \rightarrow 0.9 \\
0.2 \rightarrow 1.3 \\
0.7 \rightarrow 4.0 \\
0.2 \rightarrow 12\end{array}$ & $\begin{array}{l}2.9 \pm 0.9 \\
2.3 \pm 0.9 \\
2.8 \pm 1.6 \\
3.3 \pm 2.8\end{array}$ \\
\hline
\end{tabular}

*Inaccurate ratio in this group. 


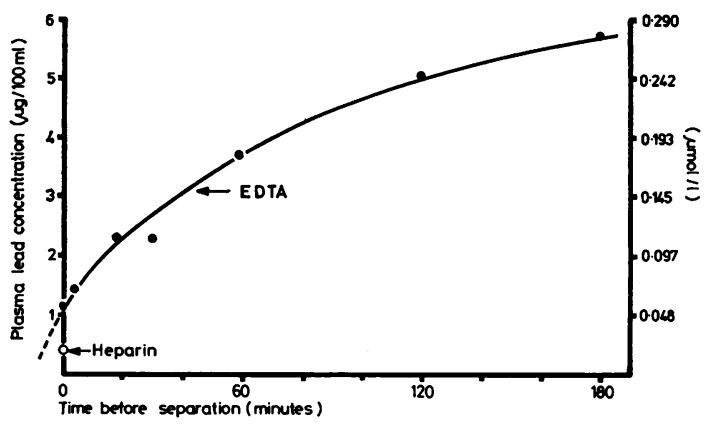

Fig 4 Elution of lead from erythrocytes by EDTA.

part added to a heparin tube and the other part to an EDTA tube. All the samples were centrifuged immediately, the blood being added to the tubes at the side of the centrifuge. The following are the percentage increases in the plasma lead concentrations obtained in the EDTA samples compared with the heparin samples for these six subjects; $370 \%$, $217 \%, 406 \%, 176 \%, 128 \%$, and $323 \%$.

This effect was further investigated by following the effect of EDTA on the plasma lead concentration with time. Blood was collected from a subject with blood lead concentration of $35 \mu \mathrm{g} / 100 \mathrm{ml}(1.69$ $\mu \mathrm{mol} / \mathrm{l})$ and divided into several aliquots, all with EDTA except one, which was collected into heparin in the usual manner. The effect on the plasma lead concentration with time is displayed in fig 4.

It can be seen that when EDTA is used it is impossible to separate the plasma from the cells quickly enough to prevent an increase in the plasma lead concentration by a factor of about two. The extent of this increase probably also depends on the exact amount of blood added to the tubes, as variation in the EDTA concentration would affect the elution rate. Chamberlain et al ${ }^{11}$ have also noted the progressive detachment of ${ }^{203} \mathrm{~Pb}$ from the red cells by EDTA in vitro.

As indicated in the introduction, there is no theoretical basis for comparing the plasma lead concentration with the blood lead concentration, and it is considered that the correct approach is to compare the plasma lead concentration with the erythrocyte lead concentration. The results of this study indicate that the mean equilibrium ratio between the plasma and cells is about $0.74 \%$.This ratio is about half that found by Cavalleri et al ${ }^{1}$ but very close to that of $0.7 \%$ obtained by Castellino and Aloj ${ }^{9}$ in their radioactive studies on rats. This value of $0.7 \%$ obtained by these investigators can be ascertained only by examining the detailed results in their table. These show a $\frac{[\mathrm{P}]}{[\mathrm{E}]}$ ratio of $2 \cdot 4 \%$ one hour after the injected dose and $0.75 \% 12$ hours later, whereas in the body of their paper Castellino and Aloj report the ratio as $4 \%$.

Despite the almost constant mean ratio obtained throughout all groups of erythrocyte lead concentrations, the scattergram shows that there is a wide variation of plasma lead concentration for each erythrocyte lead concentration. This variation between individuals is probably due, in most cases, to variations in the equilibrium partition ratio in individuals close to an equilibrium condition. It would be expected that most individuals in this series would have been subjected to a fairly steady exposure to lead and would therefore be close to equilibrium in this respect.

Some variations between individuals could be due to departures from the equilibrium condition, and such departures could be expected to occur immediately after sudden high intakes of lead. The two studies in part II indicate that after a rapid intake of lead, the $\frac{[P]}{[E]}$ ratio reaches a peak in about one hour and then falls rapidly. Equilibrium between the cells and the plasma is re-established in about 24 hours. It follows that any subjects tested within 24 hours of an unusually high lead intake may be significantly out of equilibrium and have an unusually high plasma lead concentration in relation to their erythrocyte lead concentration.

Although the subjects in part I of this study included many lead workers with excessive exposure to lead, the ones most likely to have experienced erratic lead exposure are the ones with a high erythrocyte lead concentration. The chance, however, of testing many of them within a few hours of a sudden high exposure was small. Nevertheless, this is considered to be the most likely explanation of the higher ratio in the group with erythrocyte lead concentrations greater than $199 \mu \mathrm{g} / 100 \mathrm{ml}(9.61$ $\mu \mathrm{mol} / \mathrm{l})$ and also of the four circled points in the scattergram. Two of these four subjects were maintenance men whose exposure to lead is likely to be high but intermittent. One of these two men was known to have cleaned out bag filters a few hours before being tested.

This study provides confirmation for the main conclusions drawn by Cavalleri et $a^{1}$ and strongly supports their view that plasma lead concentrations increase progressively throughout the range of blood lead concentrations commonly encountered. Plasma lead concentrations are not maintained within narrow limits as claimed by Rosen et al. ${ }^{2}$ Consequently, the conclusions of Rosen et al regarding the 
"unlimited capacity" of red cells for binding lead must be rejected, together with their claim "that correction of whole blood lead levels for haematocrit appears not to be warranted."

The multiple regression equation derived from the results of this study indicates that plasma lead concentrations are significantly related to both whole blood lead concentration and haematocrit, thereby providing strong support for the validity of the haematocrit correction.

\section{Conclusions}

The mean equilibrium ratio between plasma lead concentration and erythrocyte lead concentration has been found to be about $0.74 \%$; but there is considerable individual variation, the standard deviation of the ratio being $0.31 \%$. Under conditions of rapid absorption, when the equilibrium is disturbed, the partition ratio increases appreciably, but returns to the equilibrium value in about 24 hours.

Plasma lead concentrations are significantly related to both whole blood lead concentrations and haematocrit.

I am indebted to Ms M Donnan for the performance of the blood lead analyses, Ms C Probyn for her careful typing of the manuscript, and Dr A J Christophers for his participation in part II of the study. This paper is published with the consent of the Health Commission of Victoria.

\section{References}

${ }^{1}$ Cavalleri A, Minoia C, Pozzoli L, Baruffini A. Determination of plasma lead levels in normal subjects and in lead-exposed workers. Br J Ind Med 1978;35:21-6.

${ }^{2}$ Rosen JF, Zarate-Salvador C, Trinidad EE. Plasma lead levels in normal and lead-intoxicated children. $J$ Pediatr 1974;84:45-8.

${ }^{3}$ Aub JC, Fairhall LT, Minot AS, Reznikoff P. The transportation and deposition of lead in the body. In: Lead poisoning. Baltimore: Williams and Wilkins Co, 1926.

4 Wexler IB, Sobel AE. Spectrographic determination of lead in blood serum. Proc Soc Exp Biol Med 1935;32:719-22.

${ }^{5}$ Smith FL, Rathmell TK, Marcil GE. The early diagnosis of acute and latent plumbism. Am J Clin Pathol 1938;8: 471-508.

${ }^{6}$ Tompsett SL, Anderson AB. The plasma-cell partition of blood lead. Biochem J 1941 ;35:48-51.

${ }^{7}$ Clarkson TW, Kench JE. Uptake of lead by human erythrocytes in vitro. Biochem $J$ 1958;69:432-9.

${ }^{8}$ McRoberts W. Alteration in the fractionated blood lead concentrations in the development of inorganic lead poisoning, and the concept of the role of "lead integration" in lead absorption. J Soc Occup Med 1973;23: 3-18.

${ }^{9}$ Castellino N, Aloj S. Kinetics of the distribution and excretion of lead in the rat. BrJ Ind Med 1964;21:308-14.

${ }^{10}$ Hursh J, Schraub A, Sattler E, Hofmann H. Fate of ${ }^{212} \mathrm{~Pb}$ inhaled by human subjects. Health Phys 1969;16:257-67.

1 Chamberlain AC, Heard MJ, Little P, Newton D, Wells AC, Wiffen RD. Investigations into lead from motor vehicles. United Kingdom Atomic Energy Authority, Harwell: HMSO, 1978.

${ }^{12}$ Chisolm JJ. Lead in red blood cells and plasma. $J$ Pediatr 1974;84:163-4.

${ }^{13}$ Office of Research and Development. Air quality criteria for lead. Washington, DC: US Environmental Protection Agency, 1977. (EPA-600/8-77-017.)

14 deSilva PE, Donnan MB. Petrol vendors, capillary blood lead levels and contamination. Med J Aust 1977;1:344-7.

15 Hessel DW. A simple and rapid quantitative determination of lead in blood. Atomic Absorption Newsletter 1968;7: 55-6.

${ }^{16}$ Currie LA. Limits for qualitative detection and quantitative determination. Anal Chem 1968;40:586-93. 